\title{
O papel do enfermeiro na prevenção da infecção do sítio cirúrgico no pós- operatório imediato de cirurgia cardíaca
}

\author{
Gisele de Araújo Peixoto*, Keila da Silva*, Romária da Costa*, Suelen de Andrade Garcia*, \\ Flávia Silva de Souza, M.Sc.**
}

${ }^{*}$ Graduandos do Curso de Enfermagem do Centro Universitário Plínio Leite (UNIPLI), Niterói RJ,

**Orientadora e Docente no Centro Universitário Plínio Leite (UNIPLI), Niterói RJ

\begin{abstract}
Resumo
O presente estudo tem como motivação à vivência das autoras no campo dos cuidados ao paciente de cirurgia cardíaca, no âmbito familiar e hospitalar. Diante de tantas dificuldades que encontramos no ambiente hospitalar quanto à falta de precaução e prevenção da infecção, optou-se pela temática sobre os cuidados do enfermeiro junto ao paciente no pós-operatório imediato de cirurgia cardíaca, no qual buscaremos encontrar resposta a seguinte questão: Qual o papel do enfermeiro na prevenção da infecção do sítio cirúrgico no pós-operatório imediato de cirurgia cardíaca? Esta pesquisa tem como objeto de estudo a prevenção da infecção do sítio cirúrgico no pós-operatório imediato de cirurgia cardíaca, com objetivo de identificar as atribuiçôes do enfermeiro na prevenção dessa infecção. Esta pesquisa irá contribuir para a assistência de enfermagem direcionada aos clientes que forem submetidos à cirurgia cardíaca. Para tanto utilizaremos a metodologia descritiva qualitativa baseada em fatos relatados em literaturas da área de saúde. Observou-se que o papel do enfermeiro se insere desde o pré-operatório, através da consulta ao paciente e detecção daqueles que apresentam risco para as infecçóes, e entendemos que a lavagem das mãos é a base para a profilaxia.
\end{abstract}

Palavras-chave: cirurgia cardíaca, cuidados pós-operatórios, enfermagem pós-cirúrgica, infecção da ferida operatória.

\section{Abstract \\ Nurse's role in the prevention of surgical site infection in immediate postoperative period following cardiac surgery}

This study has as motivation the authors experience in caring patients after cardiac surgery, in family and hospital environments. Facing so many difficulties in the hospital due to lack of precaution and prevention of infection, we decided to investigate the nursing care in the immediate postoperative period of cardiac surgery. As a result, we tried to find the answer to the following question: Which is the nurse's role in the prevention of surgical site infection in the immediate postoperative period of cardiac surgery? This research aimed to study the prevention of surgical site infection in the immediate postoperative period of cardiac surgery, and to identify nurses tasks in this prevention. It is used a descriptive and qualitative methodology based on literature data of health area. It was observed that nurses role begins in the pre-operative consultation period, when it is 
detected risk for infections, and we believe that washing hands is the basis for prophylaxis.

Key-words: cardiac surgery, postoperative care, post-surgical nursing, surgical wound infection.

\section{Resumen}

\section{El papel del enfermero en la prevención de infección del sitio quirúrgico en el postoperatorio inmediato de cirugía cardíaca}

Este estudio tiene como motivación la experiencia de los autores en el campo de la atención al paciente de cirugía cardiaca, en el ámbito familiar y hospitalario. Ante tantas dificultades que encontramos en el ámbito hospitalario por la falta de precaución y de prevención de la infección, se decidió sobre la temática de la atención de los enfermeros al paciente en el postoperatorio inmediato de cirugía cardíaca, y a través de esta temática buscaremos encontrar respuestas a la siguiente pregunta: ¿Cuál es el papel de la enfermera en la prevención de infección del sitio quirúrgico en el postoperatorio inmediato de cirugía cardíaca? Esta investigación tiene como objetivo estudiar la prevención de la infección del sitio quirúrgico en el postoperatorio inmediato de cirugía cardíaca, con el fin de identificar las atribuciones de la enfermera para la prevención de esta infección. Esta investigación contribuirá en la atención de enfermería a los pacientes que se someten a cirugía cardíaca. La metodología utilizada es descriptiva, cualitativa, basada en artículos publicados en el área de la salud. Se observó que el enfermero desempeńa su papel en el preoperatorio, a través de la consulta al paciente y la detección personas en riesgo de infecciones, y que el lavado de manos es la base para la profilaxis.

Palabras-clave: cirugía cardiaca, cuidados postoperatorios, post-quirúrgica de enfermería, infección de herida quirúrgica.

\section{Introdução}

No Brasil, apenas nas duas últimas décadas o tema infecção hospitalar tem sido abordado de maneira mais efetiva e científica. Passos importantes foram dados neste sentido. O Ministério da Saúde, em 24 de junho de 1983, instituiu a portaria 196, que determina que "todos os hospitais do país deverão manter Serviço de Controle de Infecção Hospitalar (SCIH), independente da entidade mantenedora". Embora com uma série de conceitos polêmicos e imprecisos, a portaria 196 foi um passo importante na constituição de SCIH por todo país [1].

Os SCIH devem ser constituídos por, pelo menos, um médico preferencialmente infectologista, um enfermeiro, preferencialmente com formação epidemiológica, para cada 200 leitos ou fraçáo deste número. $\mathrm{O}$ período de trabalho do médico e do enfermeiro no serviço deverá ser, no mínimo, de 4 a 6 horas diárias, respectivamente, exigindo do último lotação exclusiva no programa de controle de infecção hospitalar. Embora o serviço de prevenção de infecção seja fundamental no controle, toda a equipe profissional deve ser conscientizada de que, além do médico e o enfermeiro, todos os profissionais que prestam cuidados diretos e indiretos devem ter responsabilidade na realizaçáo de um trabalho efetivo de controle de Infecção Relacionada à Assistência a
Saúde (IRAS) [1].

No que se refere à infecção de ferida cirúrgica, entende-se como período pós-operatório o período em que o paciente deixa a mesa de cirurgia até a última consulta de acompanhamento com o cirurgiáo. Esse momento pode ser táo breve quanto uma semana ou tấo longo quanto vários meses. Durante o período pós-operatório, o risco de infecçáo aumenta à medida que os equipamentos de cuidados do paciente se tornam mais complexos e conforme são utilizados mais aparelhos que rompem as barreiras anatômicas de proteção natural [2]. Após o término da cirurgia, o paciente é transferido para a unidade de pós-operatório, onde se recuperará dos efeitos anestésicos e permanecerá por um período aproximado de 24 a 48 horas [3]. É uma fase crítica para o paciente, sendo relevante a observação cuidadosa para manter as funçóes fisiológicas vitais dentro dos parâmetros da normalidade [2].

A assistência de enfermagem durante o período pós-operatório imediato concentra-se em intervençóes destinadas a prevenir ou tratar complicações. A prevenção destas no pós-operatório promove rápida convalescença, poupa tempo, reduz gastos, preocupaçóes, ameniza a dor e aumenta a sobrevida [3]. É dever da equipe de enfermagem providenciar o leito e prepará-lo para receber o paciente. A unidade deve estar composta de materiais e equipamentos 
em perfeitas condiçóes de uso, a fim de atender a qualquer situação de emergência [2].

No Brasil, apesar de muitos esforços, ainda vivemos uma realidade de múltiplas carências pelas quais passam as instituiçóes de saúde, principalmente as públicas, com falta de recursos humanos e materiais que tornam extremamente difícil a implantação de medidas eficientes no controle das IRAS. Medidas simples, como manter pias em condições de uso com sabão e papel de boa qualidade, para a lavagem das máos. Trabalhos recentes realizados em países desenvolvidos mostram que a não aderência à lavagem das mãos pelos profissionais de saúde, antes de examinarem os doentes, continua sendo o principal veículo de transmissão de microorganismos no ambiente hospitalar [1].

A infecção pós-operatória de maneira geral é um sério problema, pois pode aumentar o tempo de internação, aumentando a letalidade, a mortalidade e os custos hospitalares [4].

Dentre as infecçôes hospitalares, a infecção de sítio cirúrgico é a segunda causa mais freqüente, sendo suplantada somente pela infecção urinária [6].

Existem vários fatores que podem favorecer o aparecimento de infecção de sítio cirúrgico: fatores relacionados ao hospedeiro (obesidade, extremos de idade, duração do tempo de hospitalização pré-operatória, infecção em outros sítios, índice de gravidade da doença) e fatores relacionados ao procedimento (má vascularização, má aproximação das bordas, presença de tecido necrótico, corpo estranho, tempo cirúrgico, além de outros problemas técnicos referente ao ato cirúrgico) [6].

Nas infecçóes de sítio cirúrgico em cirurgia cardíaca incluem-se as incisóes esternais, safena e radial, que podem ser superficiais ou profundas, e as infecçôes de órgãos e espaços, como as mediastinites e as endocardites [6].

Os microrganismos mais freqüentemente associados à infecção de sítio cirúrgico são Staphylococcus aureus, estafilococos coagulase negativa e bacilos Gram-negativos [6].

Outras infecçóes que podem acometer os pacientes em pós-operatório de cirurgia cardíaca são relacionadas aos procedimentos de terapia intensiva, principalmente quando o paciente permanece por um tempo maior na UTI, em decorrência de complicação clínica e/ou cirúrgica. Temos, nesses casos, pneumonias relacionadas à ventilação mecânica, infecçóes urinárias, infecçóes relacionadas a cateteres e sepse [6].
O Center for Diseases Control (CDC), em 1999, lançou várias recomendaçóes para prevenção da infecção de sítio cirúrgico. Entre elas serão citadas as fortemente recomendadas, baseadas em estudos bem desenhados, experimentais, clínicos ou epidemiológicos: tratar todas as infecçóes pré-existentes antes do procedimento cirúrgico; não realizar tricotomia pré-operatória, a não ser que os pêlos atrapalhem a técnica cirúrgica; e utilizar antibioticoprofilaxia endovenosa em níveis bactericidas durante todo o procedimento cirúrgico e algumas horas após [6].

Medidas de controle das infecçóes em pósoperatório de cirurgia cardíaca devem ser realizadas pelo SCIH, baseadas em normas existentes para prevenção de infecção relacionada à ventilação mecânica, cateteres, infecções do trato urinário e sítio cirúrgico, as diretrizes devem ser elaboradas de acordo com as necessidades de cada serviço e suas particularidades [6].

$\mathrm{O}$ presente estudo tem como motivação à vivência das autoras no campo dos cuidados ao paciente de cirurgia cardíaca, no âmbito familiar e hospitalar. Diante de tantas dificuldades que encontramos no ambiente hospitalar quanto à falta de precaução e prevenção de infecção, optou-se pela temática sobre os cuidados do enfermeiro junto ao paciente no pós-operatório imediato de cirurgia cardíaca. A partir do exposto, tivemos como objeto a prevenção da infecção do sítio cirúrgico no pós-operatório imediato de cirurgia cardíaca. Desta forma, buscamos encontrar resposta a seguinte questão: Qual o papel do enfermeiro na prevenção da infecção do sítio cirúrgico no pós-operatório imediato de cirurgia cardíaca?

Após este questionamento buscamos alcançar o objetivo de identificar as atribuiçóes do enfermeiro na prevenção da infecção do sítio cirúrgico no pós-operatório imediato de cirurgia cardíaca. Esse assunto é relevante, pois auxilia o enfermeiro nas suas atividades de prevenção e controle de infecção.

No momento de desenvolver um estudo científico para o Trabalho de Conclusão de Curso, percebemos a oportunidade de aprofundar leituras e contribuir para a assistência de enfermagem direcionada aos clientes que forem submetidos à cirurgia cardíaca, para o ensino e pesquisa.

\section{Material e métodos}

Trata-se de um estudo descritivo, com abordagem qualitativa. A metodologia utilizada foi a 
revisão bibliográfica. O levantamento bibliográfico foi realizado mediante busca eletrônica na Biblioteca Virtual da Saúde (BVS), nas bases de dados Lilacs e BDENF, no idioma português. O recorte temporal foi de 2001 a 2007, com os seguintes descritores: cirurgia cardíaca, Enfermagem pós-cirúrgica, infecção da ferida operatória, cuidados pós-operatórios. Os descritores foram cruzados, utilizando-se o recurso boleano "and". Os critérios de inclusão foram: publicaçóes em revistas nacionais nas bases de dados já definidas, que tivessem o resumo em português e que tivessem em seu conteúdo pós-operatório de cirurgia cardíaca.

Quadro 1 - Distribuição quantitativa dos artigos encontrados nas bases de dados - $1^{a}$ etapa.

\begin{tabular}{|l|l|l|l|}
\hline \multirow{2}{*}{ DESCRITORES } & \multicolumn{3}{|l|}{ BASES DE DADOS } \\
\cline { 2 - 4 } & LILACS & BDENF & Total \\
\hline Cirurgia Cardíaca & 1017 & 57 & 1074 \\
\hline Enfermagem pós-cirúrgica & 24 & 23 & 47 \\
\hline $\begin{array}{l}\text { Infecção da ferida opera- } \\
\text { tória }\end{array}$ & 604 & 32 & 636 \\
\hline Cuidados pós-operatórios & 1049 & 125 & 1174 \\
\hline Total & 2694 & 237 & 2931 \\
\hline
\end{tabular}

Tendo encerrado esta primeira etapa da coleta de dados, observou-se a necessidade do refinamento da pesquisa. Os descritores foram cruzados utilizando-se o recurso boleano "and", como pode ser verificado no quadro 2 .

Quadro 2 - Distribuição quantitativa dos artigos encontrados nas bases de dados - $2^{a}$ etapa.

\begin{tabular}{|l|l|l|l|}
\hline \multirow{2}{*}{ DESCRITORES } & \multicolumn{3}{|l|}{ BASES DE DADOS } \\
\cline { 2 - 4 } & LILACS & BDENF & Total \\
\hline $\begin{array}{l}\text { Cirurgia Cardíaca/ Cuida- } \\
\text { dos pós-operatórios }\end{array}$ & 62 & 16 & 72 \\
\hline $\begin{array}{l}\text { Enfermagem pós-cirúrgi- } \\
\text { ca/ Cuidados pós-opera- } \\
\text { tórios }\end{array}$ & 9 & 13 & 22 \\
\hline $\begin{array}{l}\text { Infecção da ferida opera- } \\
\text { tória/ Cuidados pós- } \\
\text { operatórios }\end{array}$ & 14 & 2 & 16 \\
\hline $\begin{array}{l}\text { Cirurgia Cardíaca/ Enfer- } \\
\text { magem pós-cirúrgica }\end{array}$ & 1 & 2 & 3 \\
\hline Total & 86 & 33 & 119 \\
\hline
\end{tabular}

Nesta etapa foi feita a pré-leitura e a leitura seletiva dos resumos, quando foram eliminados os idiomas estrangeiros. Foram eliminados os artigos que antecedem o ano de 2001, e os que aparecem de forma repetida e ainda aqueles que náo se relacionavam com o objeto da pesquisa.
Tendo em vista o aperfeiçoamento desta pesquisa, realizamos uma nova busca de dados, onde acessamos diretamente a Revista da Sociedade Brasileira de Enfermeiros de Centro Cirúrgico (SOBECC) e a Revista da Sociedade Brasileira de Cardiologia (SBC). Totalizando 6 artigos.

\section{Resultados e discussão}

Os artigos foram lidos em sua íntegra e foi realizada a análise temática, da qual emergiram as seguintes categorias de análise: Influências do tempo de internação e tempo de cirurgia no aparecimento da infecção cirúrgica, Fatores predisponentes ao desenvolvimento de infecção de ferida cirúrgica e Medidas profiláticas.

\section{Influências do tempo de internaçáo e tempo de cirurgia no aparecimento da infecção cirúrgica}

Para Silva [6] e Galdeano [7] a longa permanência hospitalar pré-operatória contribui para a maior chance de infecção cirúrgica, pelo fato de que ocorrerá a substituição da flora do paciente pela flora hospitalar. O paciente psicologicamente bem adaptado, cujos sistemas orgânicos principais funcionam segundo suas necessidades, com nutrição, balanços hidroeletrolítico e ácido-básico normais, geralmente tolera uma intervenção cirúrgica. Quanto ao período transoperatório, este é considerado um período crítico para o paciente, especialmente em cirurgia cardíaca, devido à complexidade da cirurgia e procedimentos a ela inerentes, como, por exemplo, a circulação extracorpórea (CEC) e ao prolongado tempo intra-operatório. É um período caracterizado por mudanças fisiológicas gerada pelas condiçóes impostas pela cirurgia cardíaca, CEC e anestesia, podendo levar a complicaçóes no pós-operatório.

\section{Fatores predisponentes ao desenvolvimento de infecçáo de ferida cirúrgica}

Segundo Silva, Galdeano, Gelape, Rossi [6-9] vários fatores podem influenciar o estabelecimento e gravidade do processo infeccioso, como: diabetes mellitus, obesidade, desnutriçáo, extremos de idade, doenças crônicas e tabagismo são os principais fatores de risco associados ao aumento da incidência de infecção no sítio cirúrgico, devendo ser identificados preferencialmente, no período pré-operatório. 
Podemos citar, por exemplo, Van Der Berg [10], que estuda a morbi mortalidade de pacientes críticos em UTI, que aumenta, quando os níveis glicêmicos estão acima do limite de $165 \mathrm{mg} / \mathrm{dl}$. A partir desse estudo, novos protocolos de insulinoterapia estáo sendo confeccionados, com o intuito de reduzir a mortalidade e as complicaçóes das alteraçôes glicêmicas em pacientes críticos.

Os outros fatores acima citados possuem influência direta no metabolismo orgânico, na proliferação de células de cicatrizaçáo, no metabolismo de oxidação da glicose e no controle hemodinâmico, como um todo, prejudicando assim, a recuperação do paciente submetido à cirurgia cardiovascular.

\section{Medidas profiláticas e o papel do enfermeiro na prevenção de infecção de ferida cirúrgica}

Os autores Rossi e Gelape [8,9] observam que para a profilaxia das infecçóes de ferida operatória, deve-se reduzir ao máximo a contaminaçáo que tem origem nas salas de cirúrgicas. A circulação laminar do ar ambiente, utilização de raios UV, desinfecção de pisos e paredes, esterilização correta do material cirúrgico e restrição do número de pessoas que transitam nas salas de cirurgia são medidas que devem ser adotadas. A correta escovação das máos de toda a equipe envolvida nos cuidados com o paciente, especialmente da equipe cirúrgica, causa grande impacto na diminuição da contaminaçáo da ferida. Esse procedimento visa retirar a flora bacteriana transitória e diminuir a flora permanente das máos.

Consensualmente, os antimicrobianos profiláticos são recomendados, com o objetivo de diminuir a incidência de infecçóes cirúrgicas nas operaçóes classificadas como potencialmente contaminadas e contaminadas.

Mediante os resultados identificados neste estudo, observamos que é possível prevenir a infecção.

O CDC [2] estima que aproximadamente um terço de todas as infecçóes nosocomiais poderia ser evitada com programas de controle de infecção efetivos. Um programa efetivo inclui os seguintes componentes: um programa de vigilância para infecçóes hospitalares e esforços de controle rigorosos, pelo menos um profissional de controle de infecção para cada 250 leitos hospitalares, um epidemiologista hospitalar treinado e retroalimentação para cirurgióes em risco de infecçóes em sítios cirúrgicos. Infelizmente, muitos hospitais náo constituem todos os quatro aspectos exigidos e estima-se que apenas $9 \%$ das infecçóes esperadas sejam evitadas.

Os dados ou informaçóes levantadas na visita pré-operatória oferecem subsídios para a identificação de problemas ou alteraçóes relacionadas aos aspectos biopsico-sócio-espirituais do paciente e podem influenciar de maneira significativa tanto no procedimento anestésico-cirúrgico como na reabilitação do paciente. Também proporcionam a realização do planejamento de assistência contínua de enfermagem a ser uma oportunidade para a enfermeira dialogar com o paciente orientando, esclarecendo dúvidas e principalmente estabelecendo um vínculo de confiança com o paciente cirúrgico. O conhecimento das principais complicações é fundamental para promover a rápida recuperaçáo e evitar infecção hospitalar [11].

Além dos procedimentos invasivos e da defesa primária insuficiente provocada pelo trauma cirúrgico, vários outros fatores influenciam na incidência de infecção na ferida operatória, entre elas as condiçóes clínicas pré-operatória de paciente (idade, estado nutricional, doenças crônicas, etc.), as condiçôes técnicas em que a cirurgia foi realizada e a permanência hospitalar pré-operatória (quanto mais longa, maior a chance de infecção cirúrgica, pela substituição da flora do paciente pela flora hospitalar) [7].

A incidência de complicaçôes no pós-operatório imediato está geralmente associada às condiçôes clínicas pré-operatórias, a extensão e ao tipo de cirurgia, as intercorrências cirúrgicas ou anestésicas e a eficácia das medidas terapêuticas adotadas [11].

Entendemos que o enfermeiro possui um papel importante, tanto no rastreamento de paciente de risco quanto nas atividades de controle de prevenção da infecção:

- Usar as precauçóes de barreiras adequadas, observar a higiene manual correta e garantir o cuidado asséptico de cateteres intravenosos e outros equipamentos intervencionais também ajuda a reduzir as infecçôes [2];

- A incisão deve ser protegida, de preferência com gaze seca e estéril;

- Lavar as mãos antes e após realizar troca de curativo ou realizar algum contato com a ferida operatória;

- Usar técnica asséptica para a troca do curativo;

- Observar as rotinas de curativo da Unidade e as recomendaçóes técnicas para o tratamento de feridas; $\mathrm{O}$ curativo deve ser trocado antes das 24 
horas somente quando molhado, sujo ou frouxo (soltando);

- O curativo de ferida infectada deve ser feito tantas vezes quanto necessário, para manutenção do mesmo limpo e seco;

- As medidas de enfermagem destinadas a promover a cicatrização da ferida cirúrgica incluem avaliar, medir e anotar a área da ferida, para comparaçóes posteriores de evolução da mesma e alteraçóes da pele [3]

\section{Conclusão}

Esta pesquisa contribuiu de forma satisfatória, pois nos motivou a aprimorar os conhecimentos que adquirimos ao longo do curso, no que diz respeito à prevenção da infecção no pós-operatório de cirurgia cardíaca. Observou-se que, embora as infecçôes apareçam no pós-operatório imediato, o papel do enfermeiro se insere desde o pré-operatório, através da consulta ao paciente e detecção daqueles fatores que apresentam risco para as infecçôes, incluindo os pacientes que necessitam permanecer um tempo maior de internação no pré-operatório devido a complicaçóes orgânicas que precisam ser corrigidas antes da cirurgia. Entendemos que a lavagem das mãos é a base para a profilaxia e necessita ser aplicada por todos da equipe de saúde e também aos acompanhantes.

\section{Referências}

1. Fogaccia R. Veronesi. Tratado de infectologia. São Paulo: Atheneu; 2005.

2. Smeltzer $S$. Tratado de enfermagem médico-cirúrgico. 10a ed. Rio de Janeiro: Guanabara Koogan; 2005.

3. Cintra EA. Nishide VM. Nunes WA. Assistência de enfermagem ao paciente gravemente enfermo. São Paulo: Atheneu; 2005.

4. Knobel E. Condutas no paciente grave. 3a ed. São Paulo: Atheneu; 2006.

5. Abboud CS. Infecçâo em pós-operatório de cirurgia cardíaca. Revista virtual SOCESP 2001; 11(5).

6. Silva IJ. Infecção do sítio cirúrgico uma contribuiçấo de enfermagem à prevenção [tese]. Rio de Janeiro: Escola de Enfermagem Anna Nery da Universidade Federal do Rio de Janeiro; 2003. 120p.

7. Galdeano LE, Rossi LA, Nobre LF, Ignácio DS. Diagnóstico de enfermagem de pacientes no período transoperatório de cirurgia cardíaca. Rev Latinoam Enfermagem 2003;11(2):199-206.

8. Gelape CL. Infecção do sítio operatório em cirurgia cardíaca. Arq Brás Cardiol 2007;89(1):3-9.

9. Rossi LA, Tarroti FG, Carvalho EC, Manfrim A, Silva DF. Diagnóstico de enfermagem do paciente no período pós-operatório imediato. Rev Esc Enferm USP 2000;34(2):154-64.

10. Van den Berg G, Wouters P, Weekers F, et al. Intensive insulin therapy in critically ill patients. N Engl J Med 2001;345:1359-67.

11. Araújo KP, Costa KFP, Portela KMP, Barreto LS, Silva TB, Batista JCC, Jesus VS, Matos JV. Assistência de enfermagem na prevenção de complicaçôes no pósoperatório imediato [online]. Disponível em URL: http://www.webartigo.com/artigos/ 